\title{
Civil Registration, Vital Statistics and Effective Public Sector Governance and Service Delivery in Africa
}

\author{
John G. Ikubaje, Nougbodohoue Samson Bel-Aube \\ Department of Political and Economic Affairs, African Union Commission, Addis Ababa, Ethiopia \\ Email: jikubaje@gmail.com
}

Received 24 March 2016; accepted 11 April 2016; published 14 April 2016

Copyright (C) 2016 by authors and Scientific Research Publishing Inc.

This work is licensed under the Creative Commons Attribution International License (CC BY). http://creativecommons.org/licenses/by/4.0/

(c) (i) Open Access

\section{Abstract}

This paper argues that effective public service delivery is fundamental to socio-economic transformation. It emphases the significance of civil registration and vital statistics (CRVS) in planning and management of public service and administration in Africa but indicates that many national statistics offices and institutions in Africa are weak and their data are less dependable and continually impact negatively the public sector planning and management. The authors contends that members states of the African Union should prioritize strengthening their national statistics offices, domesticate and implement the following normative and other related policy frameworks to overcome the above challenges in Africa: the African charter on statistics and strategy for the harmonization of statistics in Africa, the Africa Programme on Accelerated Improvement of Civil Registration and Vital Statistics (APAI-CRVS), the African Charter on values and principles of public service and administration, the African charter on values and principles of decentralization, local governance and local development etc., the paper highlighted the element of good governance and argued that vital social statistics and civil registration were critical to operationalize these elements. Finally, the paper established the nexus among civil registration and vital statistics, public service delivery and good governance and concluded with specific recommendations on how to strengthen civil registration and vital statistics for effective public sector governance and service delivery in Africa.

\section{Keywords}

Public Sector Reform (PSR), Good Governance, Public Service, Civil Registration, Vital Statistics, Public Sector Governance, African Union, United Nations Economic Community for Africa, Lagos Plan of Action, New Partnership for Africa Development (NEPAD), Africa 2063 Development 


\section{Agenda}

\section{Introduction}

Africa countries under the supervision of the African Union (AU) have developed a fifty years development programme known as the African Union 2063 Development Agenda (African Union, 2014). In similar vein, the continental union has also developed Africa's Post-2015 Development Agenda. These development agendas are not the first in the Africa's quest for development. The Lagos Plan of Action and the New Partnership for Africa Development (NEPAD) are some of the past developmental agendas. Effective Public Service Delivery is fundamental to peace, security, stability and sustainable national and Africa development. It is for this explanation that several public sector reforms (PSRs) had taken place in many countries across the globe, particularly in African Union Member States. Despite this development, good public sector governance and effective public service delivery remain critical challenge in Africa. To overcome development challenges in Africa, Civil Registration, Vital Statistics and Effective Public Sector Governance and Service Delivery must be prioritized in all the African development agendas.

As we shall later discover in this piece, effective public service delivery and impactful public sector governance are dependent on several governance factors and or elements; civil registration and robust statistic(s) are critical to virtually all the good governance elements highlighted in the box below. In recent years, population censuses and voters registration in many African Union Member States are being challenged for inaccuracy and inadequacy.

Obviously, many National Statistic Offices (NSOs) on the continent are handicapped and their outputs are less dependable due to non-factual vital statistics data; whereas, without dependable social and governance data in place, effective public sector planning may not be feasible. In order to entrench effective public service system and service deliveries on the continent as provided for by the African Charter on the Values and Principles of Public Service and Administration (ACVPPSA) and the African Charter on the Values and Principles of Decentralization, Local Governance and Local Development (ACVPDLGLD), civil registration and vital statistics must be prioritized in all the AU Member States.

In addition to the above reference of continental normative frameworks on public service delivery in Africa, it is important to emphasize that having civil registration and vital statistics in place is critical, however, much more important is the usage of these data coupled with effective implementation of the above two frameworks in African Union Member States. As at date January 2015, only seven Member States have ratified the ACVPPSA, while the latter is yet to be ratified by any of the Member States ${ }^{1}$. For public service delivery to be impactful on Africans, utilization of civil registration and vital statistics coupled with effective implementation of the two normative frameworks are necessary conditions for public service deliveries in Member States. To drive home our argument, this paper examines what is good governance and accentuates the significance of Civil Registration and Vital Statistics on public service delivery, good governance and sustainable development, particularly in AU Member States.

The concept of good governance has assumed increased priority in international discourse on politics and development across the world thereby leading to different perspectives on its definition. On its part, the World Bank, the chief architect of good governance defines it as the manner in which power is exercise in the management of a country's economic and social resources for development (The World Bank, 1989: p. 60); while critiques of this definition contends that it is too broad and focuses mainly on national management and development, it would suffice to utilize a simpler definition that incorporates the basic elements commonly shared by most exiting definitions of good governance-the exercise of political power to manage the affairs of state. According to Mutume, good governance refer to the various processes relating to leadership, such as policy making, transparency, accountability, the protection of human rights and the relationship among the public, private and civil sectors in determining how power is exercised (Mutume, 2005: p. 11). Effective application of civil registration vital statistics policy making, transparency and accountability measurement and the type of relationship

${ }^{1}$ Although, the explanation behind the non-ratification of the African Charter on the Values and Principles of Decentralization, Local Governance and Local Development may not be unconnected with the fact that the Charter was passed by the relevant African Union Policy making Organs in June 2014. 
that exist between the private and public sector will go a long way to promote service delivery and public sector governance. Figure 1 highlights the key elements of good governance.

Governance researchers and analysts have documented that each of the above governance elements are fundamental for good governance in general and public sector management in particular and they all need relevant statistics and civil registration data to measure their utilization and effectiveness. For public service delivery to be effectively measured and evaluated in AU Member States, they must have in place a robust and reliable civil registration and statistics systems.

\section{Definitions of Civil Registration and Vital Statistics}

According to the United Nations, civil registration system is the conventional data source for generating continuous and complete vital statistics on a permanent basis (UNECA, 2012). Apart from providing vital statistics, civil registration system also provides data on population dynamics and basic health indicators, including causes of death for a country as a whole and its sub-divisions. Data generated by countries can be a source for national, sub-regional, regional and international statistical databases. It is however fundamental to emphasize at this juncture that the significance of civil registration goes beyond social statistical borders, where records of births, deaths, divorces, marriages are documented. It has become a source of useful analysis in the public services, public administration, decentralization and democratization sectors and for measuring effective public service delivery and good governance across the globe. In addition, vital statistics system has been defined as the total process of:

a) Collecting information by civil registration or enumeration on the frequency of occurrence of specified and defined vital events, as well as relevant characteristics of the events themselves and of the person or persons concerned, and

b) Compiling, processing, analysing, evaluating, presenting and disseminating these data in statistical form (UNECA, 2012). According to the United Nations, the whole list of vital events includes

- Live births,

- Adoptions,

- Legitimations,

- Recognitions;

- Deaths and foetal deaths;

- Marriages,

- Divorces,

- Separations and annulments of marriage etc.

\section{Civil Registration and Vital Statistics (CRVS) in Africa}

Civil Registration is not new in Africa ${ }^{2}$. The system and practice dates back to colonial period. It was a significant project in many colonial African States. The Colonial Governments effectively exploited civil registration and statistical data to govern their various territories. The experience however changed during the post-independent era in most of the African Union Member states due to the following among other explanations:

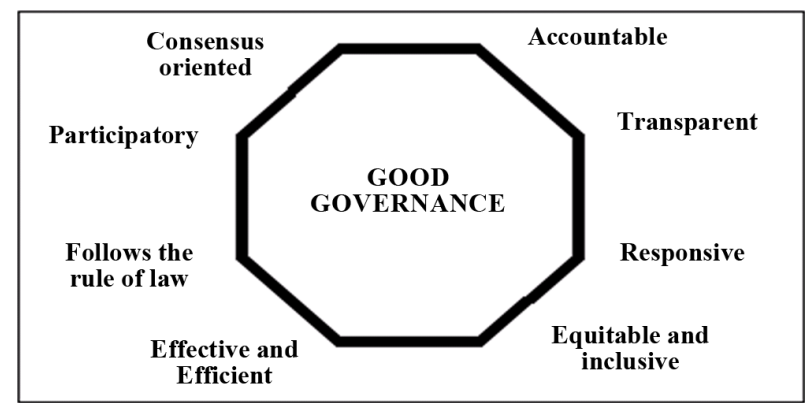

Figure 1. The key elements of good governance. Source: The World Bank Website.

${ }^{2}$ See detail in UNECA (2012), Reforming and Improving Civil Registration and Vital Statistics System in Africa: Regional Medium-Term Plan: 2010-2015. 
a) Civil Registration exercise is mostly project driven;

b) Poor coordination between National Civil Registration Authorities and the National Statistic Offices;

c) Weak national policy on CRVS;

d) Poor linkages with the national development framework;

e) Uncoordinated and fragmented utilization of CRVS;

f) Poor funding of national statistics offices and dependence on foreign development partners etc.;

g) Inadequate national, regional and continual policies on CRVS; and

h) Weak commitment by the national Government to CRVS etc.

In majority of the AU Member States, birth and death statistics are there but they are inadequate due to incomplete civil registration systems. In order to overcome this challenge, most of the Member States have resorted to using censuses and sample surveys as stop-gap measures to generate fertility and mortality estimates. The above among other factors account for why the development of a regional framework that will systematically guide CRVS system on the continent is critical.

While concluding this segment, it is noteworthy to indicate that the Africa experience on CRVS is not totally bad, some AU Member States thus have formidable national statistics and civil registration offices but majority of them need human, technical and financial capacities to function as expected and for their data to effectively influence the measurement of good public sector governance indicators in Member States.

\subsection{Africa Programme on Accelerated Improvement of Civil Registration and Vital Statistics (APAI-CRVS)}

Africa is implementing a major continental programme on the improvement of CRVS systems; known as the Africa Programme on accelerated improvement of civil registration and vital statistics (APAI-CRVS). This regional programme is implemented under the leadership of the three Pan African institutions i.e. UNECA (As the secretariat of the programme), African Union Commission (AUC) and the African Development Bank (AfDB), and partner agencies constituting the regional CRVS Core Group 2. APAI-CRVS seeks to facilitate the adoption of country-initiated strategies and programmes for improving national CRVS systems. The programme emerged from the necessity of bringing together various CRVS initiatives on the continent into a common and consolidated policy and advocacy framework.

\subsection{Progress Made by Africa in the Implementation of APAI-CRVS}

APAI-CRVS is implemented based on the policy and programmatic guidance, and mandate given by African ministers responsible for civil registration through their biennial conferences. The ministerial conference has to date been convened thrice. At the first conference held in Addis Ababa, Ethiopia in 2010, the ministers recognized CRVS as a development imperative for Africa and made clear commitments to improving the systems in their respective countries, through the provision of the necessary resources and support. During the second Conference, held in Durban, South Africa, in 2012, the ministers recommended specific, practical steps for achieving complete and efficient CRVS systems; among them being the need for all countries to undertake comprehensive assessments of CRVS systems and to develop national action plans, based on the findings of the assessment. During the third conference, the ministers made specific recognition of the health sector as a key stakeholder in the improvement of CVRS systems, and a core beneficiary of well-functioning systems. The conference called upon "WHO, in collaboration with Pan African Organizations and other partners, to intensify their efforts in developing real time death registration and causes of death information systems at country level".

The programme is now in its fifth year of implementation and has recorded significant progress in the development of CRVS systems on the continent. Some of the most outstanding achievements and challenges realized over the past five years are provided in Table 1.

\subsection{Future Perspectives of CRVS in Africa}

Civil registrations systems present significant opportunities for Africa to excel in the sustainable development agenda as well as the continental vision of the Africa we want in 50 years, as presented in the "Agenda 2063" policy and strategy document. Efficient civil registration systems in Africa would directly contribute towards improved systems of governance (this includes economic, political and social perspectives to governance), improved 
Table 1. Achievements and challenges.

\begin{tabular}{|c|c|}
\hline Areas of focus & Achievements (the programme has) \\
\hline $\begin{array}{l}\text { 1) Harness political commitment } \\
\text { across the continent }\end{array}$ & $\begin{array}{l}\text { Strengthened political commitment for the development of CRVS systems across the continent, which } \\
\text { was largely missing. This has been achieved through the biennial conference of ministers of civil } \\
\text { registration which is now an institutionalized platform }\end{array}$ \\
\hline $\begin{array}{l}\text { 2) Building/strengthening } \\
\text { partnerships in CRVS }\end{array}$ & $\begin{array}{l}\text { Strengthened coordination between civil registration authorities, national statistics offices and the } \\
\text { health sector; the adoption of CRVS as a theme of discussion at the African symposia on statistical } \\
\text { development has largely contributed to the appreciation of CRVS by national statistics offices } \\
\text { Consolidated and harmonized efforts and resources for CRVS through strengthening collaboration of } \\
\text { CRVS actors at the global, continental, and national level; The regional CRVS programme is } \\
\text { supported by a group of pan-African institutions, United Nations agencies and Non-governmental } \\
\text { organizations that form the regional CRVS Regional Core Group }\end{array}$ \\
\hline 3) Capacity building: & $\begin{array}{l}\text { Conducted trainings for CRVS functionaries. Through these trainings, a pool of CRVS experts has } \\
\text { been created and is routinely being mentored. } 31 \text { African experts were trained in May 2013, } 37 \text { experts } \\
\text { were trained in December } 2014 \text { and } 30 \text { French speaking experts were trained in February } 2015 . \\
\text { Developed a package of operational guidelines and manuals on various thematic areas. These manuals } \\
\text { have and will be useful to countries in providing guidance on the development of various aspects of } \\
\text { the systems } \\
\text { Developed a CRVS Digitization Guidebook to support countries in the endeavor to digitize their } \\
\text { CRVS systems } \\
\text { Provided direct technical support to countries }\end{array}$ \\
\hline
\end{tabular}

4) Review/assessment of the status of CRVS systems in Africa

Developed comprehensive assessment tools and guidelines that have been used by countries to undertake the assessments

Provided technical support to countries, to guide the assessment and planning processes Close to half of all countries on the continent have now undertaken an assessment of their systems while the remaining countries have committed to do so by 2016

Facilitated study tours and knowledge exchange visits between countries with weak and strong systems

5) Promoting study and research, knowledge and sharing of good practices

Developed a web based knowledge management platform that shares CRVS resources across the continent (the platform is still under development and will be launched soon)

Partnered with the International union of the scientific study of population (IUSSP) to promote study and research in CRVS

6) Strengthen mortality and cause

Developed a five-year continental strategy on improving mortality and cause of death statistics, under of death data collection systems the leadership of the WHO.

Constituted a regional reference group of mortality experts to provide policy and technical guidance on the improvement of mortality and cause of death data collection systems

\section{Key Challenges}

7) Financial Resources

The programme is significantly constrained by the lack of systematic funding for implementation of the activities set out in the Medium Term Plan. The funding for the programme, largely sourced from development partners, has been inadequate and ad hoc in nature, which constraints planning and implementation.

8) Human Resources

Inadequacy of financial resources to run the programme further constraints the ability to sustain a stable human resource structure to undertake the duties required of the secretariat. In this regard the secretariat has been under-staffed

Most countries lack mechanisms and the capacity to routinely monitor the development of their civil registration systems and can therefore not adequately report on any improvements emerging from their interventions. The lack of monitoring at country level also impacts on the ability to monitor the progress and achievements of the regional CRVS initiative.

9) Weaknesses in the monitoring framework at regional and national level To address the above challenge, the secretariat is in the process of developing a technical note that will provide systematic guidance to countries on how to assess and monitor progress of their CRVS systems.

capacity for individuals to claim their human and civil rights, better ability for governments to effect service delivery, and also better capacities in the monitoring of all human development efforts. The above makes investments into the CRVS agenda not timely, but a strategic move for the continent.

At their third conference held in Yamoussoukro, Cote d'Ivoire in February 2015, African ministers responsible for civil registration in their declaration requested African Heads of state and government to endorse the next ten years (2015-2025) to be the African decade for civil registration and vital statistics. A ten-year CRVS stra- 
tegic plan with an initial five-year costed implementation plan has been developed to this effect. The later embeds a comprehensive strategy and plan for the improvement of mortality and cause of death statistics in Africa. The leadership of UNECA in resourcing and implementation of these plans is critically required.

\section{The Nexus between CSVS, Public Service Delivery and Good Governance in Africa}

As the overarching objective of the third African Union Ministerial Conference responsible for Civil Registration is to mobilize the AU Member States to generate authentic civil registration records in realization of human and civil rights, identity management and efficient service delivery, and production of vital statistics for planning and monitoring development in the context of good governance, it is therefore germane to establish the linkage between CRVS, public service delivery and good governance in Africa. Without the requisite social and governance data (CRVS) in Member States, it will be difficult to have an impactful public sector planning and management. A faulty public sector planning and management cannot produce an effective public service delivery in any society. In order to utilize social and governance indicators to promote effective public service delivery on the continent, reliable civil registration system and accurate and comprehensive national statistics must be in place and up to date.

\section{The Roles of CRVS in Public Service in Africa}

1) Civil registration and vital statistics are the foundation for building modern public administration,

2) CRVS are critical in legal and public administration services in any Government,

3) CRVS help in generating the flow of individual and aggregate information on a continuous and provide support for public administration services,

4) It provides reliable data for redressing social abuses and exploitation, especially for disadvantaged population groups, such as children, disabled and women,

5) It lays the foundation for transactions among and between individuals and public service-rendering institutions, including establishing unique identification numbers, processing citizenship, issuing passports, maintaining electoral rolls and managing polling processes and in keeping national security,

6) It provide accurate information for implementing public policies and programmes, particularly on health and education,

7) CRVS helps in compiling and analyse various socio, cultural, and economic characteristics of marriage, divorce and other complementary variables that could be disseminated on a continuous and permanent basis for administrative use and social research,

8) It is a fundamental planning tool for accomplishment of the African Union Agenda 2063,

9) Vital statistics generated from civil registration systems are conventional data sources for measuring and providing solution to fertility and mortality estimates on a continuous and permanent basis,

10) Provision of effective public service deliveries for current population estimates and projections also depends on the availability of comprehensive and complete civil registration,

11) Civil registration will also be a conventional data source for measuring and monitoring majority of the national, regional and continental development agenda like the African Development Agenda and the global PostMDG indicators on the continent,

12) Civil registration is fundamental for national and local administration in preparing national and local government fiscal public plans and programmes.

\section{Conclusion and Policy Recommendations}

As enumerated above, CRVS is important for effective public service delivery in AU Member States. But there are measures that needed to be taken to reach the goal. The following recommendations are therefore critical in moving CRVS and effective public service delivery in Africa.

a) AU Members States that have established national statistics and civil registration offices should resource these institutions for effectiveness and efficiency; those that have not should do that without further delay,

b) AU Member States that have not ratified and domesticated the following two continental normative frameworks should do so and implement them accordingly, 
c) African Union should promote CRVS innovation and harmonization of techniques and approaches among Member States,

d) African Union should promote CRSV knowledge and share good practices,

e) African Union should build Members capacity and strengthen regional and national vital statistics production,

f) Other recommendations include continental and regional promotion of CRVS studies and research; building partnership and peer support groups, promoting country ownership and strengthening the CRVS secretariats.

\section{References}

African Union (2014). Agenda 2063, the Africa We Want (Popular Version).

Mutume, G. (2005). Beyond the Ballot: Widening African Reform. African Renewal, 18, No. 4.

The World Bank (1989). Sub-Sahara Africa from Crisis to Sustainable Growth: A Long-Term Perspective Study (p. 60). Washington DC: The World Bank.

UNECA (2012). Reforming and Improving Civil Registration and Vital Statistics System in Africa: Regional Medium-Term Plan: 2010-2015. 